\title{
Solubility of Anthracene in Binary Alcohol + 1,4-Dioxane Solvent Mixtures
}

\author{
Joyce R. Powell, Brian J. Miller, and William E. Acree, Jr.* \\ Department of Chemistry, University of North Texas, Denton, Texas 76203-0068
}

\begin{abstract}
Experimental solubilities are reported for anthracene dissolved in seven binary mixtures containing 1,4dioxane with 1-propanol, 2-propanol, 1-butanol, 2-butanol, 1-octanol, 2-methyl-1-propanol, and 3-methyl1-butanol at $25^{\circ} \mathrm{C}$. Results of these measurements are used to test two mathematical representations based upon the combined nearly ideal binary solvent (NIBS)/Redlich-Kister equation and modified Wilson model. For the systems studied, the three-parameter combined NIBS/Redlich-Kister equation was found to provide the better mathematical representation, with an overall average absolute deviation between experimental and calculated values being on the order of $0.6 \%$.
\end{abstract}

\section{Introduction}

Solid-liquid equilibrium data of organic nonelectrolyte systems are becoming increasingly important in the petroleum industry, particularly in light of present trends toward heavier feedstocks and known carcinogenicity/ mutagenicity of many of the larger polycyclic aromatic compounds. Solubility data for a number of polycyclic aromatic hydrocarbons (i.e., anthracene and pyrene) and heteroatom polynuclear aromatics (i.e., carbazole, dibenzothiophene, and xanthene) have been published in the recent chemical literature (for a listing of references see Acree $(1994,1995 a, b)$. Despite efforts by experimentalists and scientific organizations, in terms of both new experimental measurements and critically-evaluated data compilations, there still exist numerous systems for which solubility data are not readily available.

To address this problem, researchers have turned to group contribution methods and semiempirical expressions to predict desired quantities. Group contribution methods have proved fairly successful in estimating solid solubility in pure and binary solvent mixtures from structural information. Practical application, though, is limited to systems for which all group interaction parameters are known. Generally, interaction parameters are evaluated from solid-liquid and liquid-vapor equilibrium data. It is important that the data base contain as many different functional groups as possible, preferably with adequate representation from both mono- and multifunctional solute/ solvent molecules to permit evaluation of potential synergistic effects. The data base should contain sufficient experimental values near infinite dilution in the event that one wishes to determine separate interaction parameters for finite concentration and infinite dilution activity coefficient predictions.

Continued development of solution models for describing the thermodynamic properties of a solute in binary solvent systems requires that a large data base be available for assessing the applications and limitations of derived expressions. Currently, only a limited data base exists for crystalline nonelectrolyte solubility in binary solvent mixtures. For this reason, anthracene solubilities were determined in seven binary alcohol +1 ,4-dioxane solvent mixtures. Results of these measurements are used to further test the descriptive abilities of several previously derived expressions.

* To whom correspondence should be addressed. Fax: 817-565-4318. e-mail: ACREE@CAS1.UNT.EDU.

0021-9568/95/1740-1124\$09.00/0

\section{Experimental Methods}

Anthracene (Aldrich, 99.9+\%) was used as received. 1,4Dioxane (Aldrich, 99.8\%, anhydrous) was stored over molecular sieves (Aldrich, $4 \AA$ ) and distilled before use. 1-Propanol (Aldrich, 99+\%, anhydrous), 2-propanol (Aldrich, 99+\%, anhydrous), 1-butanol (Aldrich, HPLC, 99.8+\%), 2-butanol (Aldrich, 99+\%, anhydrous), 2-methyl-1-propanol (Aldrich, 99+\%, anhydrous), 3-methyl-1-butanol (Aldrich, $99+\%$, anhydrous), and 1-octanol (Aldrich, 99+\%, anhydrous) were stored over both anhydrous sodium sulfate and molecular sieves before being fractionally distilled. Gas chromatographic analysis showed solvent purities to be $99.7 \mathrm{~mol} \%$ or better. Karl Fischer titration gave water contents (mass/mass \%) of $<0.01 \%$ for all seven alcohols used. Binary solvent mixtures were prepared by mass so that compositions could be calculated to 0.0001 mole fraction.

Excess solute and solvent were placed in amber glass bottles and allowed to equilibrate in a constant temperature water bath at $(25.0+0.1)^{\circ} \mathrm{C}$ for at last 3 days (often longer). Attainment of equilibrium was verified by repetitive measurements after a mimimum of 3 additional days and by approaching equilibrium from supersaturation by preequilibrating the solutions at a higher temperature. Aliquots of saturated anthracene solutions were transferred through a coarse filter into a tared volumetric flask to determine the amount of sample and diluted quantitatively with methanol. Concentrations were determined spectrophotometrically at $356 \mathrm{~nm}$ on a Bausch and Lomb Spectronic 2000. Experimental anthracene solubilities in the seven binary alcohol +1 ,4-dioxane mixtures studied are listed in Table 1. Numerical values represent the average of between four and eight independent determinations, with the measured values being reproducible to within $\pm 1.8 \%$.

\section{Results and Discussion}

Acree and co-workers (Acree and Zvaigzne, 1991; Acree et al., 1991; Acree, 1992) suggested possible mathematical representations for isothermal solubility data based upon either the combined NIBS/Redlich-Kister model

$$
\begin{aligned}
\ln x_{\mathrm{A}}{ }^{\mathrm{sat}}=x_{\mathrm{B}}{ }^{\circ} \ln \left(x_{\mathrm{A}}{ }^{\mathrm{sat}}\right)_{\mathrm{B}}+x_{\mathrm{C}}{ }^{\circ} & \ln \left(x_{\mathrm{A}}{ }^{\mathrm{sat}}\right)_{\mathrm{C}}+ \\
& x_{\mathrm{B}}{ }^{\circ} x_{\mathrm{C}}{ }^{\circ} \sum_{i=0}^{N} S_{i}\left(x_{\mathrm{B}}{ }^{\circ}-x_{\mathrm{C}}{ }^{\circ}\right)^{i}
\end{aligned}
$$

or the modified Wilson equation (Comer and Kopecni, 1990) 
Journal of Chemical and Engineering Data, Vol. 40, No. 5, 19951125

Table 1. Experimental Mole Fraction Solubilities of Anthracene $\left(x_{\mathrm{A}}{ }^{\mathrm{sat}}\right)$ in Binary Alcohol (B) + 1,4-Dioxane (C) Solvent Mixtures at $25.0{ }^{\circ} \mathrm{C}$

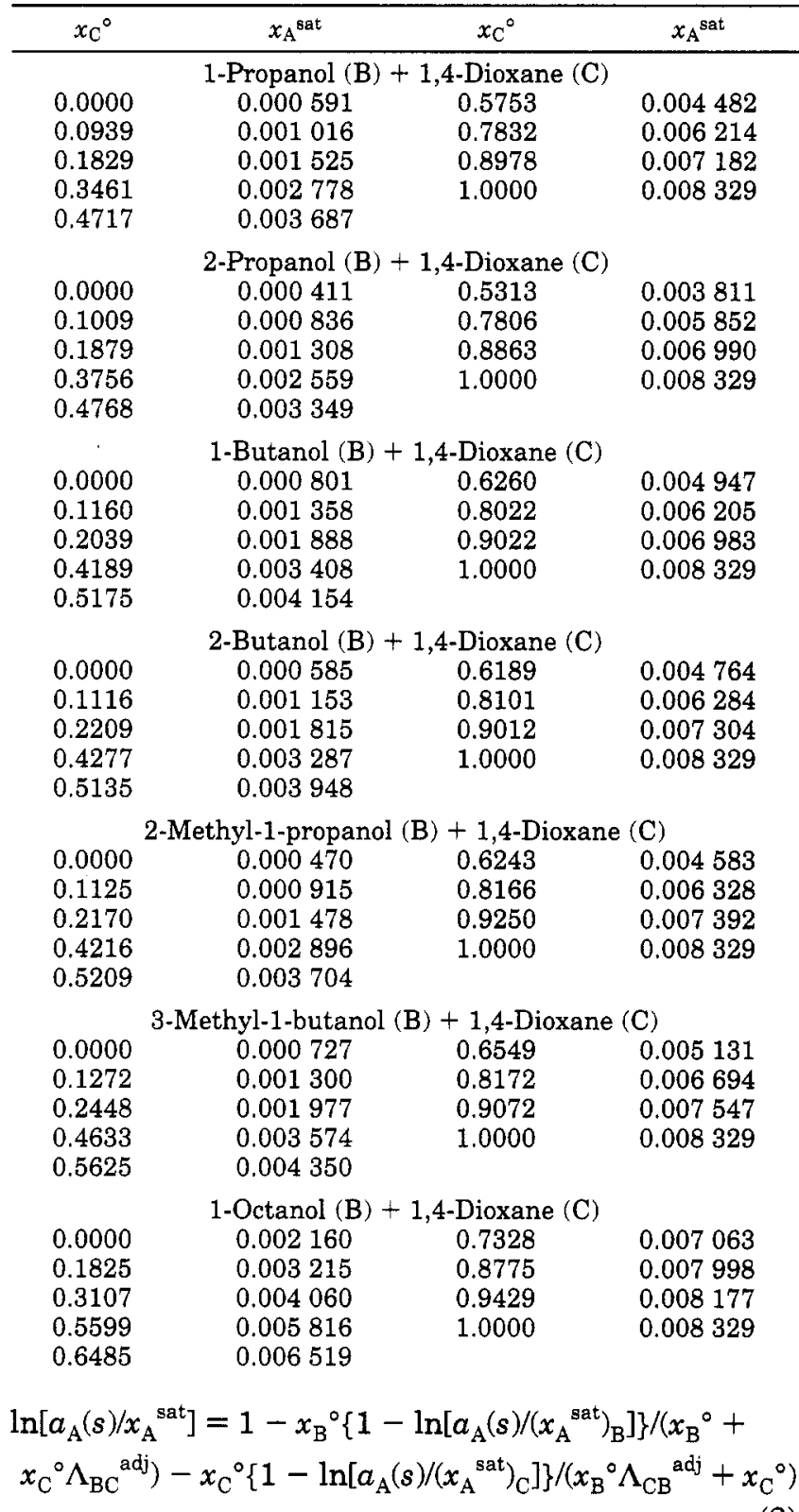

where the various $S_{i}$ and $\Lambda_{i j}$ adj "curve-fit" parameters can be evaluated via least squares analysis. In eqs 1 and $2 x_{\mathrm{B}^{\circ}}$ and $x_{\mathrm{C}}{ }^{\circ}$ refer to the initial mole fraction composition of the binary solvent calculated as if the solute were not present, $a_{\mathrm{A}}(s)$ is the activity of the solid solute, and $\left(x_{\mathrm{A}}{ }^{\text {sat }}\right)_{i}$ is the saturated mole fraction solubility of the solute in pure solvent $i$. The numerical value of $a_{\mathrm{A}}(s)=0.01049$ (Acree and Rytting, 1983) used in the modified Wilson computations was calculated from

$$
\ln a_{\mathrm{A}}(s)=-\Delta_{\mathrm{fus}} H_{\mathrm{A}}\left(T_{\mathrm{mp}}-T\right) /\left(R T T_{\mathrm{mp}}\right)
$$

where $\Delta_{\text {fus }} H_{\mathrm{A}}$ is the molar enthalpy of fusion at the normal melting point temperature of the solute, $T_{\mathrm{mp}}$.

The ability of eqs 1 and 2 to mathematically represent the experimental solubility of anthracene in the seven binary alcohol + 1,4-dioxane solvent systems is summarized in Table 2 in the form of curve-fit parameters and percent deviations in back-calculated solubilities. Careful examination of Table 2 reveals that the three-parameter combined NIBS/Redlich-Kister equation provides the bet-
Table 2. Mathematical Representation of Anthracene Solubilities in Several Binary Alcohol (B) + 1,4-Dioxane (C) Solvent Mixtures

\begin{tabular}{|c|c|c|c|c|c|c|}
\hline \multirow[b]{2}{*}{ binary solvent system } & \multicolumn{2}{|c|}{$\begin{array}{l}\text { 2-param } \\
\text { eq } 1\end{array}$} & \multicolumn{2}{|c|}{$\begin{array}{l}\text { 3-param } \\
\text { eq } 1\end{array}$} & \multicolumn{2}{|c|}{ eq 2} \\
\hline & $S_{\mathrm{i}^{\mathrm{a}}}$ & $\begin{array}{c}\% \\
\operatorname{dev}^{b}\end{array}$ & $S_{\mathrm{i}}^{\mathrm{a}}$ & $\begin{array}{c}\% \\
\operatorname{dev}^{b}\end{array}$ & $\Lambda_{i j}{ }^{\text {adj }, c}$ & $\begin{array}{c}\% \\
\operatorname{dev}^{b}\end{array}$ \\
\hline 1-propanol $+1,4$-dioxane & $\begin{array}{l}2.342 \\
1.307\end{array}$ & 1.1 & $\begin{array}{l}2.308 \\
1.305 \\
0.112\end{array}$ & 0.8 & $\begin{array}{l}2.901 \\
0.601\end{array}$ & 1.8 \\
\hline 2-propanol + 1,4-dioxane & $\begin{array}{l}2.772 \\
1.759\end{array}$ & 2.8 & $\begin{array}{l}2.559 \\
1.745 \\
0.748\end{array}$ & 0.8 & $\begin{array}{l}3.429 \\
0.837\end{array}$ & 1.1 \\
\hline 1-butanol $+1,4$-dioxane & $\begin{array}{l}1.696 \\
1.147\end{array}$ & 1.3 & $\begin{array}{r}1.792 \\
1.140 \\
-0.330\end{array}$ & 0.7 & $\begin{array}{l}2.901 \\
0.797\end{array}$ & 2.2 \\
\hline 2-butanol + 1,4-dioxane & $\begin{array}{l}2.382 \\
1.481\end{array}$ & 2.5 & $\begin{array}{r}2.178 \\
1.504 \\
0.709\end{array}$ & 0.9 & $\begin{array}{l}3.617 \\
0.949\end{array}$ & 0.7 \\
\hline $\begin{array}{l}\text { 2-methyl-1-propanol }+ \\
\text { 1,4-dioxane }\end{array}$ & $\begin{array}{l}2.390 \\
1.217\end{array}$ & 1.0 & $\begin{array}{l}2.326 \\
1.232 \\
0.210\end{array}$ & 0.5 & $\begin{array}{l}2.765 \\
0.641\end{array}$ & 0.7 \\
\hline $\begin{array}{l}\text { 3-methyl-1-butanol + } \\
\text { 1,4-dioxane }\end{array}$ & $\begin{array}{l}1.876 \\
0.604\end{array}$ & 1.3 & $\begin{array}{l}1.773 \\
0.627 \\
0.366\end{array}$ & 0.3 & $\begin{array}{l}2.065 \\
0.429\end{array}$ & 0.5 \\
\hline 1-octanol + 1,4-dioxane & $\begin{array}{r}1.014 \\
-0.077\end{array}$ & 0.7 & $\begin{array}{l}0.968 \\
0.034 \\
0.174\end{array}$ & 0.5 & $\begin{array}{l}2.198 \\
0.466\end{array}$ & 2.7 \\
\hline
\end{tabular}

${ }^{a}$ Combined NIBS/Redlich-Kister curve-fit parameters are ordered as $S_{0}, S_{1}$, and $S_{2} \cdot{ }^{b}$ Deviation $(\%)=(100 / N) \Sigma \mid\left[\left(x_{\mathrm{A}}{ }^{\text {sat }}\right)\right.$ calcd $\left.-\left(x_{\mathrm{A}}{ }^{\text {sat }}\right)^{\text {expt }}\right) \bar{V}\left(x_{\mathrm{A}}{ }^{\text {sat }}\right.$ expt $) \mid{ }^{c}$ Adjustable parameters for the Modified Wilson equation are ordered as $\Lambda_{\mathrm{BC}}$ adj and $\Lambda_{\mathrm{CB}}$ adj.

ter mathematical representation for how the solubility of anthracene varies with solvent composition. For the seven anthracene systems studied, the overall average absolute deviation between the experimental values and values calculated from the three-parameter form of eq 1 is $0.6 \%$, which is less than the experimental uncertainty. Slightly larger deviations were noted in the case of the twoparameter modified Wilson equation.

From a computational standpoint, eq 1 will likely be preferred because most research groups involved in reporting thermodynamic properties have computer programs for evaluating the Redlich-Kister coefficients. With this idea in mind, we recommend not only that the future presentation of experimental isothermal solubility data for slightly soluble solid solutes dissolved in binary solvent mixtures include a tabulation of the actual observed values but also, if possible, that the solubility data be mathematically represented by eq 1 . Realizing that a single equation will not be applicable to all systems encountered, we further suggest eq 2 as an alternative mathematical representation for systems having extremely large solubility ranges and or highly asymmetrical $\ln x_{A}$ sat versus $x_{B}{ }^{\circ}$ curves, such as the carbazole + alkane + tetrahydropyran systems reported previously (Acree et al., 1991).

\section{Literature Cited}

Acree, W. E., Jr. Mathematical Representation of Thermodynamic Properties. Part 2. Derivation of the Combined Nearly Ideal Binary Solvent (NIBS)/Redlich-Kister Mathematical Representation from a Two-Body and Three-Body Interactional Mixing Model. Thermochim. Acta 1992 , 198, 71-79.

Acree, W. E., Jr. Polycyclic Aromatic Hydrocarbons in Pure and Binary Solvents; IUPAC Solubility Data Series; Oxford University Press: Oxford, U.K., 1994; Vol. 54.

Acree, W. E., Jr. Polycyclic Aromatic Hydrocarbons: Binary Nonaque. ous Systems: Part 1 (Solutes A-E); IUPAC Solubility Data Series; Oxford University Press: Oxford, U.K., 1995a; Vol. 58.

Acree, W. E., Jr. Polycyclic Aromatic Hydrocarbons: Binary Nonaqueous Systems: Part 2 (Solutes F-Z); IUPAC Solubility Data Series; Oxford University Press: Oxford, U.K., 1995b; Vol. 59, in press.

Acree, W. E., Jr.; Rytting, J. H. Solubility in Binary Solvent Systems III: Predictive Expressions Based on Molecular Surface Areas. $J$. Pharm. Sci. 1983, 72, 292-296. 
1126 Journal of Chemical and Engineering Data, Vol. 40, No. 5, 1995

Acree, W. E., Jr.; Zvaigzne, A. I. Thermodynamic Properties of Nonelectrolyte Solutions. Part 4. Estimation and Mathematical Representation of Solute Activity Coefficients and Solubilities in Binary Solvents Using the NIBS and Modified Wilson Equations. Thermochim. Acto 1991, 178, 151-167.

Acree, W. E. Jr.; McCargar, J. W.; Zvaigzne, A. I.; Teng, I.-L. Mathematical Representation of Thermodynamic Properties. Carbazole Solubilities in Binary Alkane + Dibutyl Ether and Alkane + Tetrahydropyran Solvent Mixtures. Phys. Chem. Liq. 1991, 23, $27-35$.
Comer, J. F.; Kopecni, M. M. Prediction of Gas Chromatography Solute Activity Coefficients in Mixed Stationary Phases Based on the Wilson Equation. Anal. Chem. 1990, 62, 991-994.

Received for review March 23, 1995. Accepted May 4, $1995 .^{\otimes}$ JE950073B

Abstract published in Advance ACS Abstracts, July 1, 1995. 